\title{
Increased prevalence of autoimmune disease within C9 and FTD/MND cohorts
}

\section{Completing the picture}

\section{OPEN}

Zachary A. Miller, MD

Virginia E. Sturm, PhD

Gamze Balci Camsari, MD

Anna Karydas, BA

Jennifer S. Yokoyama,

$\mathrm{PhD}$

Lea T. Grinberg, MD, $\mathrm{PhD}$

Adam L. Boxer, MD,

$\mathrm{PhD}$

Howard J. Rosen, MD

Katherine P. Rankin, PhD

Maria Luisa Gorno-

Tempini, MD, PhD

Giovanni Coppola, MD

Daniel H. Geschwind,

$\mathrm{MD}, \mathrm{PhD}$

Rosa Rademakers, PhD

William W. Seeley, MD

Neill R. Graff-Radford,

$\mathrm{MBBCH}, \mathrm{FRCP}$

(Lond)

Bruce L. Miller, MD

Correspondence to

Dr. Miller:

zmiller@memory.ucsf.edu

\section{ABSTRACT}

Objective: To determine the prevalence of autoimmune disease in symptomatic C9ORF72 (C9) mutation carriers and frontotemporal dementia with motor neuron disease (FTD/MND) cohorts.

Methods: In this case-control study, we reviewed the clinical histories of 66 patients with FTD/ MND and 57 symptomatic C9 carriers (24 overlapping cases), a total of 99 charts, for history of autoimmune disease. The prevalence of autoimmune disease in C9 and FTD/MND cohorts was determined by $\chi^{2}$ and Fisher exact comparisons between the combined C9 and FTD/MND group with normal control, Alzheimer disease, and progressive supranuclear palsy cohorts, as well as comparisons within C9 and FTD/MND cohorts.

Results: Our combined C9 and FTD/MND cohort has a $12 \%$ prevalence of nonthyroid autoimmune disease. The prevalence of nonthyroid autoimmune disease in C9 and FTD/MND is similar to the rates in previously detailed progranulin and semantic variant primary progressive aphasia cohorts and elevated in comparison to previously collected normal control and typical Alzheimer disease cohorts, as well as a newly screened progressive supranuclear palsy cohort. Furthermore, the types of autoimmune disease in this combined C9 and FTD/MND cohort cluster within the same 3 categories previously described in progranulin and semantic variant primary progressive aphasia: inflammatory arthritides, cutaneous conditions, and gastrointestinal disorders.

Conclusions: The association between selective autoimmune disease and neurodegenerative disorders unified by the underlying pathology frontotemporal lobar degeneration with TDP-43-positive inclusions (FTLD-TDP) extends to C9 and FTD/MND cohorts, providing further evidence that select autoimmune inflammation may be intrinsically linked to FTLDTDP pathophysiology. Neurol Neuroimmunol Neuroinflamm 2016;3:e301; doi: 10.1212/ NXI.0000000000000301

\section{GLOSSARY}

$\mathbf{A D}=$ Alzheimer disease; $\mathbf{A L S}=$ amyotrophic lateral sclerosis; $\mathbf{b v F T D}=$ behavioral variant frontotemporal dementia; $\mathbf{C 9}=$ C9ORF72; FTD = frontotemporal dementia; FTLD = frontotemporal lobar degeneration; MMSE = Mini-Mental State Examination; MND = motor neuron disease; $\mathbf{N C}=$ normal control; PGRN = progranulin; PSP = progressive supranuclear palsy; svPPA = semantic variant primary progressive aphasia; TDP-43 = TAR DNA-binding protein 43; TNF $=$ tumor necrosis factor.

Previously, we reported a relationship between systemic autoimmune inflammation in frontotemporal dementia (FTD) progranulin (PGRN) mutation carriers and patients with semantic variant primary progressive aphasia (svPPA). ${ }^{1}$ Pathologically, PGRN and svPPA typically display frontotemporal lobar degeneration (FTLD) with abnormal TAR DNA-binding protein 43 (TDP-43)-positive aggregates (FTLD-TDP). ${ }^{2}$ FTLD-TDP pathology is also the pathology present in a majority of patients with amyotrophic lateral sclerosis (ALS), ${ }^{2}$ in nearly $100 \%$ of behavioral variant FTD (bvFTD) cases with features of motor neuron disease (FTD/MND), ${ }^{3}$

From the Memory and Aging Center (Z.A.M., V.E.S., A.K., J.S.Y., L.T.G., A.L.B., H.J.R., K.P.R., M.L.G.-T., W.W.S., B.L.M.) and Department of Pathology (L.T.G., W.W.S.), University of California, San Francisco; Departments of Neurology (G.B.C., N.R.G.-R.) and Neuroscience (R.R.), Mayo Clinic, Jacksonville, FL; and Department of Neurology (G.C., D.H.G.), David Geffen School of Medicine, University of California, Los Angeles, CA.

Funding information and disclosures are provided at the end of the article. Go to Neurology.org/nn for full disclosure forms. The Article Processing Charge was paid by Neurology ${ }^{\circledR}$ Neuroimmunology and Neuroinflammation.

This is an open access article distributed under the terms of the Creative Commons Attribution-NonCommercial-NoDerivatives License 4.0 (CC BY-NC-ND), which permits downloading and sharing the work provided it is properly cited. The work cannot be changed in any way or used commercially without permission from the journal. 
and in patients with chromosome 9 open reading frame 72 (C9ORF72 or C9) mutations. ${ }^{4}$ C9 represents the single greatest genetic contribution to both ALS and bvFTD (with or without MND). ${ }^{5}$ While strong associations between autoimmune disease and ALS have been appreciated for decades, ${ }^{6-8}$ the cooccurrence and prevalence of autoimmune disease in C9 and FTD/MND are unknown. Therefore, we screened our cohorts of C9 and FTD/MND to determine whether a similar pattern of autoimmune disorders, as observed in our other FTLD-TDP populations, was present.

METHODS Standard protocol approvals, registrations, and patient consents. All participants underwent informed consent to share their clinical data for research purposes. The study of patient clinical data was approved by the human research committee at the University of California, San Francisco and Jacksonville Mayo Clinic. All participants were enrolled in these academic center's research studies of FTD and related disorders between March 1999 and October 2013.

Participants. We retrospectively identified 2 substantially overlapping cohorts, a clinically defined FTD/MND group, and a symptomatic C9 FTD group. Seventy-one patients had clinical features that conformed to bvFTD consensus criteria ${ }^{9}$ and displayed features of MND. ${ }^{10}$ Five patients were excluded because of limited charting that did not include full medical histories, leaving a total of 66 patients in our FTD/MND group. C9 testing was positive in 24 of these individuals, whereas 42 were either negative or without available results (30 negative, 11 without testable samples, and one with results pending). Separately, we identified 67 symptomatic individuals who were positive for $\mathrm{C} 9$ mutations and one individual with FTD/MND whose nephew was positive for C9. We excluded

\section{Table 1 Screen of autoimmune conditions}

$\begin{array}{lll}\text { Addison disease } & \text { Guillain-Barré syndrome } & \text { Primary biliary cirrhosis } \\ \text { Ankylosing spondylitis } & \text { Hashimoto thyroiditis } & \text { Psoriasis } \\ \text { Autoimmune hemolytic anemia } & \text { Inclusion body myositis } & \text { Reactive arthritis } \\ \text { Behçet disease } & \begin{array}{l}\text { Immune thrombocytopenic } \\ \text { purpura }\end{array} & \text { Rheumatoid arthritis } \\ \text { Celiac disease } & \text { Localized scleroderma } & \text { Sarcoidosis } \\ \text { Chorea minor } & \text { Lichen sclerosus } & \text { Sjögren syndrome } \\ \text { Chronic lymphocytic colitis } & \text { Lupoid hepatitis } & \text { Systemic lupus } \\ \text { Chronic rheumatic heart disease } & \text { Multiple sclerosis } & \text { Systemic sclerosis } \\ \text { or rheumatic fever } & \text { Myasthenia gravis } & \text { Thyroid disease } \\ \text { Crohn disease } & \text { Pernicious anemia } & \text { Transverse myelitis } \\ \text { Dermatomyositis } & \text { Polyarteritis nodosa } & \begin{array}{l}\text { Type } 1 \text { diabetes } \\ \text { mellitus }\end{array} \\ \text { Discoid lupus } & & \text { Ulcerative colitis } \\ \text { Granulomatosis with polyangiitis } & \text { Polymyalgia rheumatica } & \text { Vitiligo } \\ \text { Grave disease } & \text { Polymyositis } & \end{array}$

8 individuals whose records did not include full medical histories and 3 who had no evidence for FTD, for a total of 57 C9-positive individuals: 33 with bvFTD only and 24 with FTD/MND.

For comparison, in our previous study, we identified 186 normal controls (NCs) and 158 individuals with typical Alzheimer disease (AD). ${ }^{1}$ For an FTLD-tau disease control group, we screened a group of 107 patients who met criteria for progressive supranuclear palsy (PSP), ${ }^{11}$ as patients with PSP demonstrate high clinicopathologic correlations with underlying FTLD-tau pathology. ${ }^{12}$

\section{Identification and classification of autoimmune conditions.}

We screened patients' charts for evidence of autoimmune disease using a similar autoimmune disease collection previously employed $^{1}$ (table 1). As done previously, autoimmune diseases were categorized into thyroid and nonthyroid disorders. The rationale for splitting autoimmune disorders into different categories is manifold, as autoimmune diseases are not unitary conditions (specific patterns of autoimmune disease are well known to aggregate or cluster together within families or within individuals); some patients present with features that would qualify for the diagnosis of a spectrum of autoimmune disease (e.g., rhupus - rheumatoid arthritis and lupus), and in some cases, genetics of autoimmune risk reveal anticorrelations between conditions (such as a polymorphism where one allele variant increases risk of rheumatoid arthritis while the other variant affects likelihood of developing thyroid disease). Furthermore, as we had shown previously, rates of thyroid disease did not discriminate svPPA and PGRN FTLD-TDP disease groups from our disease and healthy control cohorts. ${ }^{1}$

Statistical analysis. We compared differences between the combined C9 and FTD/MND cohort and our previously collected NC and AD control cohorts and a newly collected PSP cohort. We also compared the following groups within the C9 and FTD/MND cohort: C9-positive individuals with FTD and without MND (C9 FTD only) vs C9-positive with FTD/ MND (C9 FTD/MND) vs unknown or negative C9 status and FTD/MND diagnoses (FTD/MND without C9). Analysis of variance was used to test for significance for continuous variables such as age, education, and Mini-Mental State Examination (MMSE) score across diagnostic groups. For categorical variables such as sex and ethnicity, $\chi^{2}$ tests were performed. Prevalence and comparison of autoimmune disease among the diagnostic groups were assessed for statistical significance using $\chi^{2}$ tests and Fisher exact test when frequencies were less than 5 in select groups.

RESULTS C9 and FTD/MND combined cohort vs control groups. The combined C9 and FTD/MND group was younger and comprised a greater percentage of men than the $\mathrm{NC}, \mathrm{AD}$, and PSP populations $(p<0.001 ; p=0.003)$. As expected, all disease groups performed worse than the NC cohort on the MMSE. Comparisons of the combined C9 and FTD/ MND cohort with $\mathrm{NC}, \mathrm{AD}$, and PSP groups ${ }^{1}$ showed a statistically significant elevation of nonthyroid autoimmune disease in the $\mathrm{C} 9$ and FTD/MND group $(p=0.02)$ but not in thyroid only or total autoimmune disease rates (figure and table 2).

C9 FTD only vs C9 FTD/MND vs FTD/MND without C9. There were no differences in race, education, or MMSE score; however, both MND cohorts had 


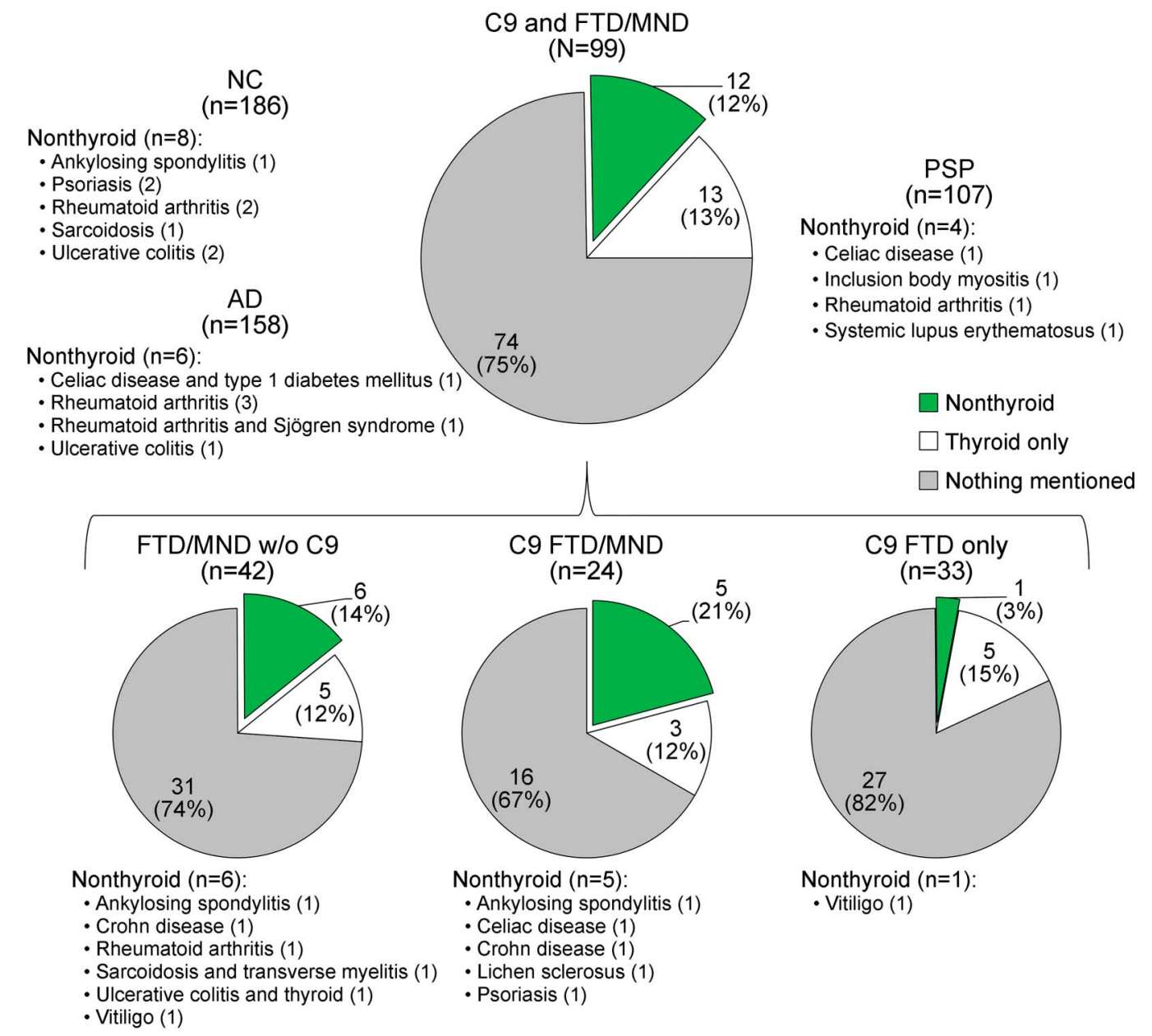

Retrospective chart review of autoimmune conditions in AD, C9, FTD/MND, NC, and PSP cohorts. Above, prevalence of autoimmune diseases across neurodegenerative cohorts (AD vs total C9 and FTD/MND vs NCs vs PSP), and below, between C9 and FTD/MND groups (FTD/MND without C9 vs C9 FTD/MND vs C9 FTD only). Nothing mentioned refers to individuals for whom there is no mention of any condition found within the screening collection instrument. When individuals possess both a thyroid disorder and another autoimmune disease, they are assigned to the nonthyroid autoimmune category, so as to avoid being counted twice. Thyroid only refers to those who only have thyroid spectrum disorders. $A D=A l z h e i m e r$ disease; C9 = C9ORF72 mutation carrier; FTD = frontotemporal dementia; MND = motor neuron disease; NC = normal control; PSP = progressive supranuclear palsy.

significantly more men than the C9 FTD-only cohort $(p=0.03)$. There were no differences in any of the autoimmune prevalence rates (thyroid, nonthyroid, and total) between C9 and FTD/ MND cohorts (C9 FTD only vs C9 FTD/MND vs FTD/MND without C9 groups) (figure and table 3).

Combined FTLD-TDP cohort. Combining the results of our $\mathrm{C} 9$ and FTD/MND screening with the results of our prior PGRN and svPPA screening yields a large high-likelihood FTLD-TDP cohort consisting of 265 individuals, $12 \%$ of whom possess a nonthyroid autoimmune disorder (table 4).

DISCUSSION An increasing number of reports have shown that C9 loss of function in murine models recapitulates human autoimmune disease. ${ }^{13-16}$ In this study, we formally investigated autoimmune disease prevalence within $\mathrm{C} 9$ and FTD/MND cohorts and, consistent with our prior PGRN and svPPA study, observed elevated rates of select nonthyroid autoimmune disorders within symptomatic C9 and FTD/ MND cohorts compared to NCs, typical AD, and new to this study, an FTLD-tau control group, PSP. The specific types of autoimmune diseases in the C9 and FTD/MND group cluster within the same 3 general autoimmune groups as previously described: inflammatory arthritides, cutaneous conditions, and gastrointestinal disorders. ${ }^{1}$ The design of this collection, with one genetic cohort (C9) and the other presumed idiopathic in underlying etiology (FTD/MND) was structured to be analogous to our prior study. ${ }^{1}$ The fact that the prevalence and type of 
Table 2 C9 and FTD/MND vs control cohort

\begin{tabular}{|c|c|c|c|c|c|}
\hline \multirow[b]{2}{*}{ Diagnostic group } & \multicolumn{5}{|c|}{ Comparisons across neurodegenerative cohorts } \\
\hline & NC & $A D$ & Total C9 and FTD/MND & PSP & p \\
\hline Age at first visit, $y$, mean $\pm S D(n)$ & $65.6 \pm 9.9(186)$ & $65.7 \pm 9.8(158)$ & $59.5 \pm 9.4(99)$ & $66.6 \pm 7.6(107)$ & $<0.001^{\mathrm{a}}$ \\
\hline Sex, \% female (n) & $54(100 / 186)$ & $49(77 / 158)$ & 32 (31/99) & $43(46 / 107)$ & $0.003^{a}$ \\
\hline Race, \% Caucasian (n) & $92.4(171 / 185)$ & $89.4(135 / 151)$ & $92.3(84 / 91)$ & $82.9(87 / 105)$ & NS \\
\hline Education, $y$, mean $\pm S D(n)$ & $16.2 \pm 2.4(168)$ & $15.7 \pm 3.7(134)$ & $15.5 \pm 3(79)$ & $15.3 \pm 3.5(104)$ & NS \\
\hline MMSE at first visit, mean \pm SD (n) & $29.2 \pm 1.5(162)$ & $20 \pm 6.3(121)$ & $24 \pm 6.1(74)$ & $26 \pm 4.6(81)$ & $<0.001^{\mathrm{a}}$ \\
\hline Autoimmune disease, $\%$ total (n) & $16(30 / 186)$ & $17(27 / 158)$ & $25(25 / 99)$ & $17(18 / 107)$ & NS \\
\hline Autoimmune disease, \% nonthyroid ( $n$ ) & $4(8 / 186)$ & $4(6 / 158)$ & $12(12 / 99)$ & $4(4 / 107)$ & $0.02^{\mathrm{a}}$ \\
\hline Autoimmune disease, $\%$ thyroid total ( $n$ ) & $12(22 / 186)$ & $13(21 / 158)$ & $14(14 / 99)$ & $13(14 / 107)$ & NS \\
\hline
\end{tabular}

Abbreviations: $A D=$ Alzheimer disease; $C 9=$ C9ORF72; FTD = frontotemporal dementia; MMSE = Mini-Mental State Examination; MND = motor neuron disease; NC = normal control; NS = not significant; $\mathrm{PSP}=$ progressive supranuclear palsy.

${ }^{\text {a }}$ Significant value.

autoimmune disease within and without genetic and idiopathic groups aligns so strongly across both this and our prior study ${ }^{1}$ presupposes that the cooccurrence of autoimmune disease reflects some fundamental characteristic of FTLD-TDP pathophysiology.

Despite the limitations of this study, we believe our retrospective chart collection more likely underestimates rather than overestimates the co-occurrence of autoimmune disease. While overall numbers are small, this collection represents a substantial reporting of $\mathrm{C} 9$ and FTD/MND. Combining all our highlikelihood FTLD-TDP cohorts together produces an even more substantial group to investigate our claims, and in this combined cohort, we continue to see an overrepresentation of select diseases clustering in the same general autoimmune categories (table 3). Separation of the $\mathrm{C} 9$ cohort into individuals with and without motor neuron symptoms was done to facilitate direct comparison of C9 FTD/MND to
FTD/MND without C9. Dividing the C9 cohort into groups with and without motor neuron symptoms also provides a window to explore characteristics that may pertain to phenotypic vulnerability, as the reason why some individuals develop an isolated behavioral syndrome while others a predominant motor neuron condition might inform us about disease pathophysiology. The combined C9 cohort has $11 \%$ autoimmune disease, all of which arise from the C9 FTD/MND cohort except for one autoimmune disease case in the C9 FTD-only cohort. Despite this, there were no significant differences in the prevalence of autoimmune disease between the C9 FTD-only vs C9 FTD/MND group. Larger collections are needed to identify whether presence of autoimmune disease influences the targeting of C9-mediated neurodegenerative disease.

The association of autoimmunity with C9 and FTD/MND has grounding in biological and epidemiologic observations made independently in ALS

Table 3 C9 FTD only vs C9 FTD/MND vs FTD/MND without C9

\begin{tabular}{|c|c|c|c|c|}
\hline \multirow[b]{2}{*}{ Diagnostic group } & \multicolumn{4}{|c|}{ Comparisons between $\mathrm{C} 9$ and FTD/MND cohorts } \\
\hline & FTD/MND without C9 & C9 FTD/MND & C9 FTD only & $p$ \\
\hline Age at first visit, $y$, mean $\pm S D(n)$ & $61.7 \pm 9.4(42)$ & $57 \pm 9.2(24)$ & $58.6 \pm 9.2(33)$ & NS \\
\hline Sex, \% female (n) & $29(12 / 42)$ & $17(4 / 24)$ & $48(16 / 33)$ & $0.03^{a}$ \\
\hline Race, \% Caucasian (n) & $85(40)$ & $100(22)$ & $97(29)$ & NS \\
\hline Education, $y$, mean $\pm S D(n)$ & $16.4 \pm 2.6(36)$ & $14.8 \pm 2.8(24)$ & $14.7 \pm 3.8(19)$ & NS \\
\hline MMSE at first visit, mean \pm SD (n) & $22.6 \pm 7.4(34)$ & $26.3 \pm 3.6(24)$ & $23.1 \pm 5.2(16)$ & NS \\
\hline Autoimmune disease, \% total (n) & $26(11 / 42)$ & $33(8 / 24)$ & $18(6 / 33)$ & NS \\
\hline Autoimmune disease, \% nonthyroid (n) & $14(6 / 42)$ & $21(5 / 24)$ & $3(1 / 33)$ & NS \\
\hline Autoimmune disease, \% thyroid total (n) & $14(6 / 42)$ & $13(3 / 24)$ & $15(5 / 33)$ & NS \\
\hline
\end{tabular}

Abbreviations: $\mathrm{C9}=$ C9ORF72; FTD $=$ frontotemporal dementia; MMSE $=$ Mini-Mental State Examination; MND $=$ motor neuron disease; NS = not significant.

a Significant value. 
Table 4 Autoimmune diseases in high-likelihood FTLD-TDP cohorts

\begin{tabular}{|c|c|c|c|c|c|c|}
\hline & $\begin{array}{l}\text { C9 and } \\
\text { FTD/MND } \\
\text { ( } \mathrm{n}=99), \mathrm{n}\end{array}$ & $\begin{array}{l}\text { PGRN and } \\
\text { svPPA }{ }^{1} \\
\text { ( } n=166), n\end{array}$ & $\begin{array}{l}\text { Combined } \\
\text { FTLD-TDP } \\
\text { (n = 265), n }\end{array}$ & $\begin{array}{l}\text { Combined } \\
\text { FTLD-TDP } \\
\text { prevalence, \% }\end{array}$ & $\begin{array}{l}\text { Estimated } \\
\text { general } \\
\text { population } \\
\text { prevalence, \% }\end{array}$ & $\begin{array}{l}\text { Estimated } \\
\text { odds ratio }\end{array}$ \\
\hline \multicolumn{7}{|l|}{ Nonthyroid autoimmune disease } \\
\hline Vitiligo & 2 & 3 & 5 & 1.9 & $0.4^{1}$ & 4.8 \\
\hline Psoriasis & 1 & 3 & 4 & 1.5 & $0.1^{1}$ & 15 \\
\hline Rheumatoid arthritis & 1 & 3 & 4 & 1.5 & $0.9^{1}$ & 1.7 \\
\hline Sarcoidosis & $1^{\mathrm{a}}$ & 3 & 4 & 1.5 & $0.001-0.04^{1}$ & $37.5-1,500$ \\
\hline Sjögren syndrome & - & $3^{b}$ & 3 & 1.1 & $0.01-0.3^{1}$ & $3.7-110$ \\
\hline Ankylosing spondylitis & 2 & - & 2 & 0.8 & $0.03-0.9^{37}$ & $0.9-26.7$ \\
\hline Celiac disease & 1 & 1 & 2 & 0.8 & $0.03-0.8^{1}$ & $1-26.7$ \\
\hline Crohn disease & 2 & - & 2 & 0.8 & $0.2^{38}$ & 4 \\
\hline Lichen sclerosus & 1 & 1 & 2 & 0.8 & Unknown ${ }^{1}$ & NA \\
\hline Systemic lupus erythematosus & - & $2^{b, c}$ & 2 & 0.8 & $0.02^{1}$ & 40 \\
\hline Chronic lymphocytic colitis & - & 1 & 1 & 0.4 & $0.06^{1}$ & 6.7 \\
\hline Discoid lupus & - & $1^{\mathrm{c}}$ & 1 & 0.4 & $0.4-0.8^{1}$ & $0.5-1$ \\
\hline Transverse myelitis & $1^{\mathrm{a}}$ & - & 1 & 0.4 & Unknown & NA \\
\hline Type 1 diabetes mellitus & - & 1 & 1 & 0.4 & $0.2^{1}$ & 2 \\
\hline Ulcerative colitis & 1 & - & 1 & 0.4 & $0.2^{38}$ & 2 \\
\hline \multicolumn{7}{|l|}{ Autoimmune clusters } \\
\hline Inflammatory arthritides & 4 & $12^{\mathrm{b}, \mathrm{c}}$ & 16 & & & \\
\hline Cutaneous conditions & 4 & $8^{\mathrm{b}, \mathrm{c}}$ & 12 & & & \\
\hline Gastrointestinal disorders & 4 & 2 & 6 & & & \\
\hline
\end{tabular}

Abbreviations: C9 = C9ORF72; FTD = frontotemporal dementia; FTLD = frontotemporal lobar degeneration; MND = motor neuron disease; PGRN = progranulin; svPPA = semantic variant primary progressive aphasia; TDP = TAR DNAbinding protein.

$\mathrm{a}, \mathrm{b}, \mathrm{c}$ Overlapping individuals.

and more recently in FTD. Speculations of a primary role for systemic inflammation in the pathogenesis of MND have been made following observations of elevated systemic inflammatory markers in serum and CSF, and proliferation of activated microglia, astrocytes, monocytes, and $\mathrm{T}$ cells in spinal cord and brain tissue. $^{7,17-20}$ There is considerable precedence of association between systemic autoimmune inflammation and $\mathrm{MND},{ }^{6,7}$ including a recent, large epidemiologic study investigating the prevalence of autoimmune diseases preceding ALS,${ }^{8}$ which reflected on the substantial overlap between their findings and those in our initial FTD and autoimmune disease report. ${ }^{1}$

Regarding the connections between systemic inflammation and FTLD-TDP disease, although the mechanism of action for C9 remains unclear, C9 was identified as 1 of 3 loci that modified the efficacy of tumor necrosis factor $\alpha$ (TNF- $\alpha$ ) blocking agents in rheumatoid arthritics, ${ }^{21}$ implicating an immune function years before neurologic significance was appreciated. In support of this, 4 recent studies demonstrate profound disruptions of immune homeostasis exemplified by human systemic autoimmune disease in C9 knockout mice. ${ }^{13-16}$ Specifically, lysosomal trafficking defects, cytokine elevations, widespread myeloid expansion, and $\mathrm{T}$ cell activation ${ }^{13-15}$ have been observed, as well as upregulation of autoantibody production (anti-nuclear antibody, anti-cardiolipin, anti-double stranded DNA, anti-Smith, and anti-rheumatoid factor antibodies) in a manner highly evocative of human systemic lupus erythematosus. ${ }^{13,15}$

Further evidence linking immune system dysfunction in FTD and ALS stems from genetic studies, including identification of the HLA-DRA/DRB5 and $R A B 38 / C T S C$ regions in $\mathrm{FTD}^{22}$ and $T B K 1$ mutations in ALS, ${ }^{23} \mathrm{FTD},{ }^{24}$ and FTD/MND. ${ }^{25}$ The HLA-DRA/DRB5 region encodes several major histocompatibility complex class II proteins responsible for adaptive immunity and is specifically implicated in the pathogenesis of autoimmunity. ${ }^{22}$ Both RAB38 and CTSC function in autophagy and lysosomal pathways. ${ }^{22} R A B 38$, in particular, is a member of the Rab family of proteins and encodes an endosomal trafficking protein expressed in neurons and melanocytes. ${ }^{26}$ Patients with vitiligo frequently 
develop autoantibodies to Rab38, ${ }^{27}$ and vitiligo is the most prevalent autoimmune disease observed in our combined FTLD-TDP population (table 3). C9 functions as an activator of several Rab proteins, ${ }^{28}$ possibly accounting for the observed lysosomal trafficking disruptions in knockout models. ${ }^{14} T B K 1$ is a master regulator of innate immune system signaling (TNF-mediated nuclear factor $\kappa \mathrm{B}$ activation) having prominent roles in autophagy and inflammation. ${ }^{23}$ All told, recent genetics emphasize dysregulation along the spectrum of endocytic and endosomal trafficking pathways to major histocompatibility complex class II antigen presentation ${ }^{29}$ in FTD and ALS.

While not a primary outcome of this study, we observed a disproportionate number of men in the total C9 cohort (65\% male; 37/57), driven by the C9 FTD/MND subgroup (83\% male; 20/24). C9 is an autosomal gene and as such should not show any sex preference. As FTD may be more likely misdiagnosed in women, ${ }^{30}$ one potential explanation for this sex discrepancy is that we observed a relative lack of women in the combined C9 cohort from a possible referral bias. In general, bvFTD tends to be more male than female, ${ }^{31}$ and given that our C9 FTD-only cohort has a near equal male/female ratio ( $52 \%$ male; $17 / 33)$, it would seem unlikely that a referral bias is affecting our bvFTD collection. Another possibility is that there is an overabundance of men in our FTD/ MND cohort. If this were the case, it would presume that male sex confers selective vulnerability to MND within C9 carriers. Increased male prevalence in ALS is a well-known epidemiologic occurrence, ${ }^{6}$ and increased penetrance as well as earlier age at ALS onset has been shown in male C9 carriers. ${ }^{32}$ Before the discovery of $\mathrm{C}$, the same sex differences, of equal sex ratios in bvFTD and male predominance in FTD/ MND cohorts, had been reported. ${ }^{33}$ Finally, the fact that this observed increased male sex ratio in our C9 FTD/MND cohort was also reflected in our FTD/ MND without C9 cohort, serves as an internal validation of our observations in the C9 FTD/MND group. Together, these results strongly support an interaction between sex and C9 phenotypic expression that warrants further investigation.

Another observed sex difference is that, of the 12 patients with C9 and FTD/MND who had autoimmune disease, 75\% (9/12) were men. While some autoimmune diseases are more likely to occur in men, most autoimmune diseases are more likely to occur in women. ${ }^{34}$ Typically, anywhere between $60 \%$ and $80 \%$ of persons with autoimmune disease are female. ${ }^{34,35}$ In keeping with this, $60 \%(12 / 20)$ of individuals with autoimmune disease in our prior svPPA and PGRN study were female. ${ }^{1}$ While this sex difference in autoimmune rates in our C9 and FTD/MND group might simply reflect the increased male demographics of the entire cohort, it is noteworthy that a greater proportion of the autoimmune diseases in this group are of the male-predominant type. Specifically, one-third (4/12) of those with autoimmune disease within the C9 and FTD/MND cohort possessed a male-predominant autoimmune disease such as ankylosing spondylitis, ulcerative colitis, and sarcoidosis, ${ }^{34}$ whereas only $15 \%$ (3/20) of the svPPA and PGRN autoimmune disease cohort possessed one of these male-predominant autoimmune diseases. It has been suggested that male-predominant autoimmune diseases produce greater innate immune system activation and autoantibody production than femalepredominant diseases ${ }^{35}$ - conspicuous features of C9 mouse ablation models. ${ }^{13-15}$ Given this, it may be possible that FTLD-TDP disorders will provide a model for disentangling sex differences within autoimmune diseases. As is the case with our other findings, much larger collections will be needed to determine whether these patterns persist.

The increased prevalence of select autoimmune diseases within FTD and ALS reported here and elsewhere $^{1,8}$ along with observations of widespread immunologic disruptions reminiscent of human autoimmune disease in $\mathrm{PGRN}^{36}$ and C9 knockout mice $^{13-16}$ illustrate how immunodysregulation may be intrinsically linked to FTLD-TDP pathophysiology. While we show some initial results supporting a role for autoimmunity in distinguishing FTLDTDP from FTLD-tau pathologies, direct comparisons of larger groups of high-likelihood TDP and tau cohorts are needed to determine the role of autoimmunity for its potential predictive value. To date, all the reported autoimmune conditions here, and in our prior study, ${ }^{1}$ preceded enrollment in our research programs. While this might imply that immunodysregulation occurs before neurodegeneration, the directionality of this association remains unclear. The observation that ablation of C9 produces immunologic but not neurologic disease suggests that these effects of C9 dysfunction may be dissociable. ${ }^{13-16} \mathrm{We}$ suspect that the co-occurrence of immunologic disorders within neurologic diseases reflects a shared vulnerability to each, and as such, deciphering the exact mechanisms underlying this connection will likely have near term implications for understanding, treating, and preventing autoimmune and neurodegenerative diseases alike.

\section{AUTHOR CONTRIBUTIONS}

Dr. Zachary Miller: conceptualization and design of the study, collection, analysis, and interpretation of the data, drafting and revising the manuscript. Dr. Sturm: analysis and interpretation of the data and revising the manuscript. Dr. Gamze Balci Camsari: analysis and interpretation of the data and revising the manuscript. Ms. Karydas: collection of data and revising the manuscript. Dr. Yokoyama: interpretation of the data and revising the manuscript. Dr. Grinberg: interpretation of the data and revising the manuscript. Dr. Boxer: analysis and interpretation of the 
data and revising the manuscript. Dr. Rosen: data collection, drafting and revising the manuscript. Dr. Rankin: design and conceptualization of the study, analysis and interpretation of the data, drafting and revising the manuscript. Dr. Gorno-Tempini: data collection, drafting and revising the manuscript. Dr. Coppola: funded by R01 AG026938; analysis and interpretation of the data and revising the manuscript. Dr. Geschwind: funded by the Alzheimer's Disease Research Center of California (ARCC) grant 03-7527 and R01AG026938; analysis and interpretation of the data and revising the manuscript. Dr. Rademakers: analysis and interpretation of the data, revising the manuscript. Dr. Seeley: design and conceptualization of the study, analysis and interpretation of the data, drafting and revising the manuscript. Dr. Graff-Radford: design and conceptualization of the study, analysis and interpretation of the data, drafting and revising the manuscript. Dr. Bruce Miller: design and conceptualization of the study, analysis and interpretation of the data, drafting and revising the manuscript.

\section{ACKNOWLEDGMENT}

This work was supported by NIH grants (K23 AG048291, P01 AG019724, P50 AG023501, and P50 AG16574) and its contents are solely the responsibility of the authors and do not necessarily represent the official views of the National Institute on Aging or NIH. Additional funds come from programs including the Consortium for Frontotemporal Dementia Research, the Tau Research Consortium, and the Larry Hillblom Foundation grants 2002/2J and 2007/2I.

\section{STUDY FUNDING}

This work was supported by NIH grants (K23 AG048291, P01 AG019724, P50 AG023501, and P50 AG16574).

\section{DISCLOSURE}

Z.A. Miller holds a patent for Dynamic and Adjustable Portable X-ray Filter Grid, Dynamic and Adjustable Filter Grids, received research support from NIH, the Bluefield Project. V.E. Sturm received travel funding and speaker honoraria from International Conference on Frontotemporal Dementias, received research support from NIA, Larry L. Hillblom Foundation, Global Brain Health Institute. G.B. Camsari and A. Karydas report no disclosures. J.S. Yokoyama is an associate editor for the Journal of Alzheimer's Disease, received research support from Quest Diagnostics, NIH-NIA, Association for Frontotemporal Degeneration, Larry L. Hillblom Foundation. L.T. Grinberg received travel funding from Controversies in Neurology, served on the editorial board for Journal of Alzheimer's Disease, served as associate editor for Frontiers in Dementia, Cell and Tissue Banking, received research support from AVID Radiopharmaceuticals, NIA-NIH, Alzheimer's Association, Rainwater Foundation. A.L. Boxer served on the scientific advisory board for Alector, Asceneuron, and Delos, received travel funding from the International Society for CNS Clinical Trials Methodology, the Movement Disorders Society, the Association for Frontotemporal Degeneration, Fidelity Biosciences Research Institute, and the Tau Consortium, consulted for AbbVie, Ionis, Janssen, Merck, received research support from Avid, Biogen, BMS, C2N, Cortice, Forum, Genentech, Janssen, Pfizer, Eli Lilly, Roche, TauRx, NIH, the Tau Research Consortium, the Bluefield Project to Cure Frontotemporal Dementia, Corticobasal Degeneration Solutions, and the Alzheimer's Association. H.J. Rosen received research support from Quest Diagnostics, NIH, Atlantic Philanthropies, Global Brain Health Institute. K.P. Rankin received travel funding and/or speaker honoraria from American Academy of Neurology, International Neuropsychological Society, Houston Methodist, Houston Alzheimer's Association, received research support from Quest Diagnostics, NIH/ NIA, NIH/NINDS, UCSF/REAC, UCSF Chancellor's Fund, Weill Foundation, the Larry L. Hillblom Foundation, the Rainwater Charitable Foundation. M.L. Gorno-Tempini served as section editor for NeuroImage: Clinical, received research support from NIH/NINDS, NIH/ NIA, John Douglas French Alzheimer's Foundation, Alzheimer's Association, Larry L. Hillblom Foundation, Koret Family Foundation, McBean Family Foundation. G. Coppola received research support from the Consortium for Frontotemporal Dementia Research, Adelson Medical Research Foundation, the Tau Consortium, the Easton Consortium, CHDI, Takeda Pharmaceutical Company. D.H. Geschwind served on the scientific advisory board for Ovid Therapeutics Inc., SynapDx Corp, Roche, received travel funding from Roche, Novartis, served on the editorial board for Cell, Molecular Autism, Molecular Neuropsychiatry, Science, Translational Psychiatry, holds patents for Peripheral Gene Expression Biomarkers for Autism, Genetic Risk Factor for Neurodegenerative Disease, Compositions and Methods for Diagnosing and Treating Brain Cancer and Identifying Neural Stem Cells, Genetic Variants Underlying Human Cognition: Novel Diagnostic and Therapeutic Targets, Peripheral Gene Expression Biomarkers for Autism, Brain Gene Expression Changes Associated with Autism Spectrum Disorders, Full Biomarkers in Friedreich's Ataxia (provisional patent application), Signaling Networks Causing Neurodevelopmental Disorders in Human Neurons, Genes Dysregulated in Autism, Potential Biomarkers and Therapeutic Pathways, Peripheral Gene Expression Biomarkers for Autism, A Genetic Target for Treatment of Individuals with Neurocognitive Spectrum Disorders, Neuronal Regeneration, Frataxin KnockDown Mouse, Jakmip1 Knockout Mouse, Cyfip1 Transgenic Mouse, received publishing royalties from Oxford University Press, consulted for OVID Therapeutics Ltd., SynapDx, Roche Group, received research support from Takeda Pharmaceutical Company, NIH/NIMH, NIH/ NICHD, CIRM TR2-01814, NIH/NINDS, NIH/NIA, the Simons Foundation, Adelson Medical Research Foundation, Fidelity Foundation, Ovid Therapeutics. R. Rademakers holds a patent for Detecting and Treating Dementia, Methods and Materials for Detecting and Treating Dementia, received research support from NIH, Mayo Clinic Udall Center of Excellence, ALS Therapy Alliance, Consortium for Frontotemporal Dementia, Florida State Alzheimer's Disease Research Grant. W.W. Seeley served on the editorial board for Annals of Neurology, Acta Neuropathologica, Neuroimage Clinical, consulted for Bristol-Myers Squibb, received research support from NIA, NINDS, John Douglas French Alzheimer's Disease Foundation, Consortium for Frontotemporal Dementia Research, Tau Consortium; John D. and Catherine T. MacArthur Foundation, Alzheimer's Disease Drug Foundation, Association for Frontotemporal Dementia. N.R. Graff-Radford served on the scientific advisory board for Cytox Consultation, served on the editorial board for Alzheimer Disease and Therapy, received publishing royalties from UpToDate, received research support from TauRx, Lille, Biogen, Axovant, NIA. B.L. Miller served on the scientific advisory board for Tau Consortium, the John Douglas French Foundation, the Larry Hillblom Foundation, SAB National Institute for Health Research in Dementia, Stanford University, served as editor for NeuroCase, served on the editorial board for Cambridge University Press, Guilford Publications, Inc., receives publishing royalties from Cambridge, Elsevier, Guilford, received research support from NIA, CMS. Go to Neurology.org/nn for full disclosure forms.

Received April 5, 2016. Accepted in final form October 3, 2016.

\section{REFERENCES}

1. Miller ZA, Rankin KP, Graff-Radford NR, et al. TDP43 frontotemporal lobar degeneration and autoimmune disease. J Neurol Neurosurg Psychiatry 2013; 84:956-962.

2. Mackenzie IRA, Neumann M, Baborie A, et al. A harmonized classification system for FTLD-TDP pathology. Acta Neuropathol 2011;122:111-113.

3. Snowden J, Neary D, Mann D. Frontotemporal lobar degeneration: clinical and pathological relationships. Acta Neuropathol 2007;114:31-38.

4. Ng AS, Rademakers R, Miller BL. Frontotemporal dementia: a bridge between dementia and neuromuscular disease. Ann NY Acad Sci 2015;1338:71-93.

5. Ling S, Polymenidou M, Cleveland DW. Converging mechanisms in ALS and FTD: disrupted RNA and protein homeostasis. Neuron 2013;79:416-438.

6. Appel SH, Stockton-Appel V, Stewart SS, Kerman RH. Amyotrophic lateral sclerosis: associated clinical disorders and immunological evaluations. Arch Neurol 1986;43: 234-238. 
7. Appel SH, Smith RG, Engelhardt JI, Stefani E. Evidence for autoimmunity in amyotrophic lateral sclerosis. J Neurol Sci 1993;118:169-174.

8. Turner MR, Goldacre R, Ramagopalan S, Talbot K, Goldacre MJ. Autoimmune disease preceding amyotrophic lateral sclerosis: an epidemiologic study. Neurology 2013; 81:1222-1225.

9. Neary D, Snowden JS, Gustafson L, et al. Frontotemporal lobar degeneration: a consensus on clinical diagnostic criteria. Neurology 1998;51:1546-1554.

10. Brooks BR. El Escorial World Federation of Neurology criteria for the diagnosis of amyotrophic lateral sclerosis. Subcommittee on Motor Neuron Diseases/Amyotrophic Lateral Sclerosis of the World Federation of Neurology Research Group on Neuromuscular Diseases and the El Escorial "Clinical limits of amyotrophic lateral sclerosis" workshop contributors. J Neurol Sci 1994;124(suppl): 96-107.

11. Litvan I, Agid Y, Calne D, et al. Clinical research criteria for the diagnosis of progressive supranuclear palsy (SteeleRichardson-Olszewski syndrome): report of the NINDSSPSP international workshop. Neurology 1996;47:1-9.

12. Josephs KA, Petersen RC, Knopman DS, et al. Clinicopathologic analysis of frontotemporal and corticobasal degenerations and PSP. Neurology 2006;66:41-48.

13. Atanasio A, Decman V, White D, et al. C9orf72 ablation causes immune dysregulation characterized by leukocyte expansion, autoantibody production, and glomerulonephropathy in mice. Sci Rep 2016;6:23204.

14. O’Rourke J, Bogdanik L, Yáñez A, et al. C9orf72 is required for proper macrophage and microglial function in mice. Science 2016;351:1324-1329.

15. Burberry A, Suzuki N, Wang JY, et al. Loss-of-function mutations in the C9ORF72 mouse ortholog cause fatal autoimmune disease. Sci Transl Med 2016;8:347ra93.

16. Sudria-Lopez E, Koppers M, de Wit M, et al. Full ablation of C9orf72 in mice causes immune system-related pathology and neoplastic events but no motor neuron defects. Acta Neuropathol 2016;132:145-147.

17. Poloni M, Facchetti D, Mai R, et al. Circulating levels of tumour necrosis factor-[alpha] and its soluble receptors are increased in the blood of patients with amyotrophic lateral sclerosis. Neurosci Lett 2000;287:211-214.

18. Kuhle J, Lindberg R, Regeniter A, et al. Increased levels of inflammatory chemokines in amyotrophic lateral sclerosis. Eur J Neurol 2009;16:771-774.

19. McGeer P, McGeer E. Inflammatory processes in amyotrophic lateral sclerosis. Muscle Nerve 2002;26:459-470.

20. Butovsky O, Siddiqui S, Gabriely G, et al. Modulating inflammatory monocytes with a unique microRNA gene signature ameliorates murine ALS. J Clin Invest 2012;122: 3063-3087.

21. Liu C, Batliwalla F, Li W, et al. Genome-wide association scan identifies candidate polymorphisms associated with differential response to anti-TNF treatment in rheumatoid arthritis. Mol Med 2008;14:575-581.

22. Ferrari R, Hernandez DG, Nalls MA, et al. Frontotemporal dementia and its subtypes: a genome-wide association study. Lancet Neurol 2014;13:686-699.
23. Cirulli ET, Lasseigne BN, Petrovski S, et al. Exome sequencing in amyotrophic lateral sclerosis identifies risk genes and pathways. Science 2015;347:1436-1441.

24. Pottier C, Bieniek KF, Finch N, et al. Whole-genome sequencing reveals important role for TBK1 and OPTN mutations in frontotemporal lobar degeneration without motor neuron disease. Acta Neuropathol 2015;130:77-92.

25. Freischmidt A, Wieland T, Richter B, et al. Haploinsufficiency of TBK1 causes familial ALS and fronto-temporal dementia. Nat Neurosci 2015;18:631-636.

26. Bultema JJ, Ambrosio AL, Burek CL, Di Pietro SM. BLOC-2, AP-3, and AP-1 proteins function in concert with Rab38 and Rab32 proteins to mediate protein trafficking to lysosome-related organelles. J Biol Chem 2012; 287:19550-19563.

27. Waterman EA, Gawkrodger DJ, Watson PF, Weetman AP, Kemp EH. Autoantigens in vitiligo identified by the serological selection of a phage-displayed melanocyte cDNA expression library. J Invest Dermatol 2010;130: 230-240.

28. Zhang D, Iyer LM, He F, Aravind L. Discovery of novel DENN proteins: implications for the evolution of eukaryotic intracellular membrane structures and human disease. Front Genet 2012;3:283.

29. Mantegazza AR, Magalhaes JG, Amigorena S, Marks MS. Presentation of phagocytosed antigens by MHC class I and II. Traffic 2013;14:135-152.

30. Woolley JD, Khan BK, Murthy NK, Miller BL, Rankin $\mathrm{KP}$. The diagnostic challenge of psychiatric symptoms in neurodegenerative disease: rates of and risk factors for prior psychiatric diagnosis in patients with early neurodegenerative disease. J Clin Psychiatry 2011;72:126-133.

31. Ratnavalli E, Brayne C, Dawson K, Hodges JR. The prevalence of frontotemporal dementia. Neurology 2002;58: $1615-1621$.

32. Williams KL, Fifita JA, Vucic S, et al. Pathophysiological insights into ALS with C9ORF72 expansions. J Neurol Neurosurg Psychiatry 2013;84:931-935.

33. Hodges JR, Davies R, Xuereb J, Kril J, Halliday G. Survival in frontotemporal dementia. Neurology 2003;61: 349-354.

34. Ji J, Sundquist J, Sundquist K. Gender-specific incidence of autoimmune diseases from national registers. J Autoimmun 2016;69:102-106.

35. Fairweather D, Frisancho-Kiss S, Rose NR. Sex differences in autoimmune disease from a pathological perspective. Am J Pathol 2008;173:600-609.

36. Tang W, Lu Y, Tian QY, et al. The growth factor progranulin binds to TNF receptors and is therapeutic against inflammatory arthritis in mice. Science 2011; 332:478-484.

37. Helmick CG, Felson DT, Lawrence RC, et al. Estimates of the prevalence of arthritis and other rheumatic conditions in the United States: part I. Arthritis Rheum 2008; 58:15-25.

38. Kappelman MD, Rifas-Shiman SL, Kleinman K, et al. The prevalence and geographic distribution of Crohn's disease and ulcerative colitis in the United States. Clin Gastroenterol Hepatol 2007;5:1424-1429. 


\section{Neurology ${ }^{\oplus}$ \\ Neuroimmunology \& Neuroinflammation}

Increased prevalence of autoimmune disease within C9 and FTD/MND cohorts: Completing the picture

Zachary A. Miller, Virginia E. Sturm, Gamze Balci Camsari, et al.

Neurol Neuroimmunol Neuroinflamm 2016;3;

DOI 10.1212/NXI.0000000000000301

This information is current as of October 28, 2016

Neurol Neuroimmunol Neuroinflamm is an official journal of the American Academy of Neurology.

Published since April 2014, it is an open-access, online-only, continuous publication journal. Copyright $\odot$ 2016 American Academy of Neurology. All rights reserved. Online ISSN: 2332-7812.

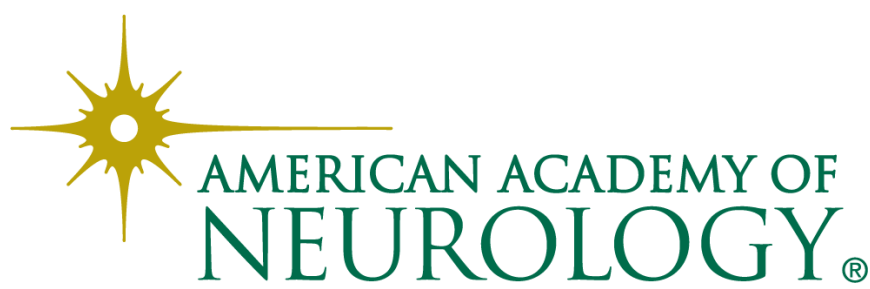




\section{Updated Information \& Services}

References

Citations

Subspecialty Collections

\section{Permissions \& Licensing}

Reprints including high resolution figures, can be found at: http://nn.neurology.org/content/3/6/e301.full.html

This article cites 38 articles, 7 of which you can access for free at: http://nn.neurology.org/content/3/6/e301.full.html\#\#ref-list-1

This article has been cited by 3 HighWire-hosted articles: http://nn.neurology.org/content/3/6/e301.full.html\#\#otherarticles

This article, along with others on similar topics, appears in the following collection(s):

Amyotrophic lateral sclerosis

http://nn.neurology.org//cgi/collection/amyotrophic_lateral_sclerosis_ Autoimmune diseases

http://nn.neurology.org//cgi/collection/autoimmune_diseases

Case control studies

http://nn.neurology.org//cgi/collection/case_control_studies

Frontotemporal dementia

http://nn.neurology.org//cgi/collection/frontotemporal_dementia

Information about reproducing this article in parts (figures,tables) or in its entirety can be found online at:

http://nn.neurology.org/misc/about.xhtml\#permissions

Information about ordering reprints can be found online:

http://nn.neurology.org/misc/addir.xhtml\#reprintsus

Neurol Neuroimmunol Neuroinflamm is an official journal of the American Academy of Neurology.

Published since April 2014, it is an open-access, online-only, continuous publication journal. Copyright $\odot$ 2016 American Academy of Neurology. All rights reserved. Online ISSN: 2332-7812.

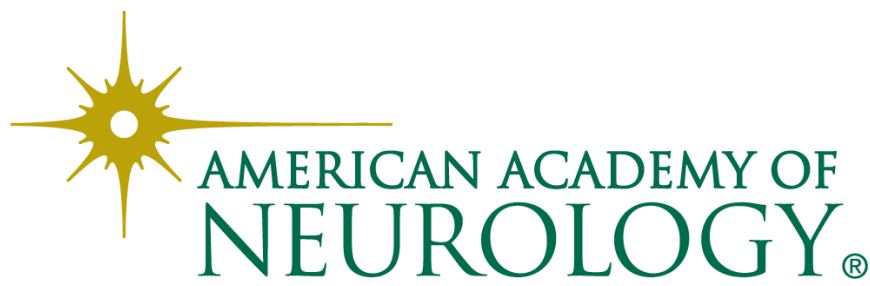

